\title{
AMBIENT LEARNING
}

The experience of ambient technologies in eLearning

Bernhard Kölmel and Sébastien Kicin

CAS Software AG, Wilhelm-Schickard-Str. 12, 76131 Karlsruhe, Germany

Abstract: AMBIENT LEARNING is a new market validation project exploring the applications and hardware needed in creating networked context aware environments for ambient services and testing them in the eLearning area.

Key words: AMBIENT LEARNING; eLearning; use cases

A recent European Survey report (Jane Massy, 2002) revealed some disastrous facts about eLearning: "61\% of all respondents rated the overall quality of eLearning negatively - as 'fair' or 'poor'." According to recent studies by IT Skills Research Programme and consulting firm OvumHolway the take-up of eLearning in Europe has been rather slow due to a combination of numerous factors/barriers like fear of miss-investment, lack of time and expertise, inadequate accessibility and usability, failure to integrate eLearning with the work and life process or even inadequate lowquality learning content. The survey "Lifelong learning: a citizen's view" brings to the point the key main obstacles to lifelong learning: time and money. Exactly at these identified obstacles starts the new AMBIENT LEARNING project, merging eLearning objectives with new Ambient Intelligences opportunities. Using recently established technologies for enabling ambient intelligence and context aware services, its objective is to provide a pragmatic, easy-to-use eLearning service, which allows any time, any where and any how access to personalised, high quality learning content.

The service will be demonstrated along three use cases.

1. Busy professionals lack time for vocational training and therefore target articles out of scientific or professional magazines for learning. The AMBIENT LEARNING service will enable to structure and define personal training needs. Based on specific contexts (for instance driving to a customer) and personal interests the learning content will be 
downloaded from scientific or industrial content providers to mobile devices and read with a Text-To-Speech engine.

2. Innovative software based solutions and applications are not widely deployed in European SMEs. This is mainly due to daily operation and lack of financial resources for affording consultants able to tailor these systems to their specific needs. The service will allow to deliver an interactive learning unit explaining system functionalities to potential customers. Moreover an interactive testing of the customers know-how will suggest context-based in-depth training or training repetitions.

3. Service employees on external duty, have often no possibility to join standard training activities or use state-of-the-art eLearning applications due to often changing environments (devices, networks etc.). The offered service will allow for context-based access to key learning units.

The developped LMS will provide complete Catalogue and Management functionality. The ability to list any online learning, event and any content type (electronic Books, SCORM-based learning objects, databases etc.) will enable an holistic one stop shop. The system is based on a service-oriented architecture (SOA) made up of components and interconnections that stress interoperability and location transparency.

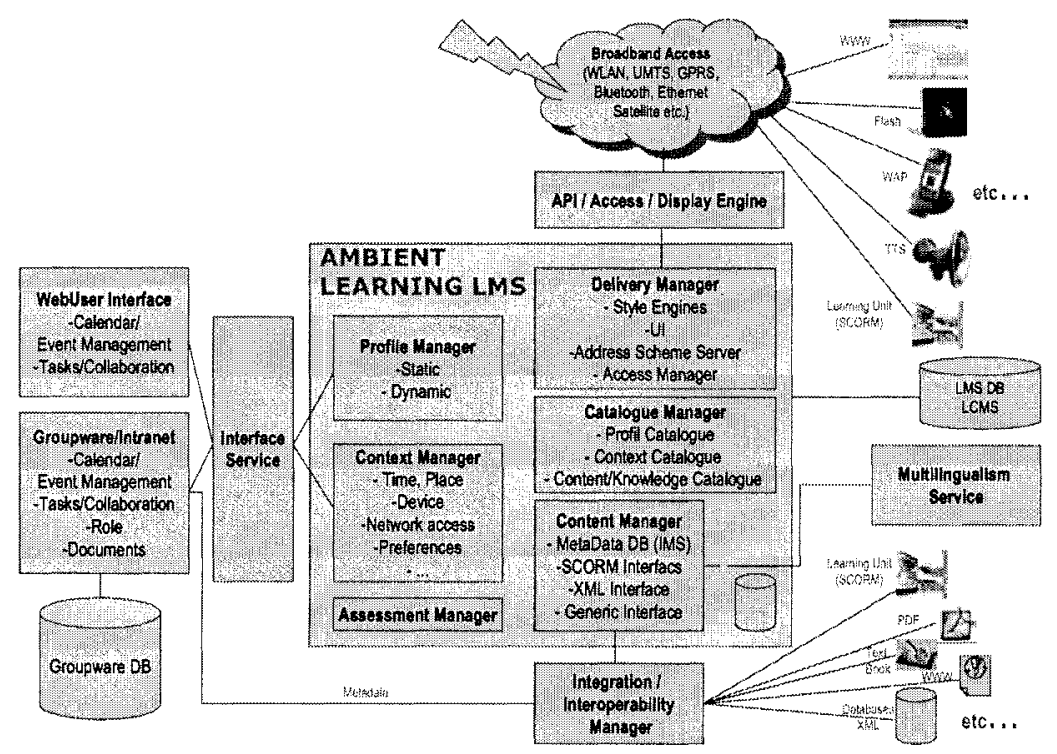

Figure 1. AMBIENT LEARNING architecture

Jane Massy - "Quality and eLearning in Europe", 2002

Office for Official Publications of the European Communities (Luxembourg) - "Lifelong learning: citizens' views", 2003 